\title{
CONTOS E ENCANTOS INFANTIS RIBEIRINHOSAMAZÔNIDOS NO COTIDIANO ESCOLAR
}

\author{
Edilma de Soura \\ Maritza Maciel Castrillon Maldonado
}

Resumo

Ziguezagueando entre as feituras infantis ribeirinhasamazônidas compomos este texto. Assumimos o compromisso de narrar as singularidades de crianças que fogem de interpretações e itinerários prefixados, pois em nosso encontro nos detemos em suas operações astuciosas e clandestinas pouco observadas no mundo tomado pelo capitalismo. $\mathrm{Na}$ esteira da filosofia da diferença, vimos produzindo diferenciações aos modos de pesquisar com as crianças e as infâncias. Para tanto, produzimos nosso trajeto investigativo por intermédio da cartografia deleuziana, na busca das vivências e das narrativas infantis. Nessa investidura, às margens de um rio em meio à floresta amazônica, encontramos as narrativas de experiências singulares que subvertem a lógica de sentido de um lugar para as crianças e as infâncias na escola.

Palavras-chave: crianças ribeirinhasamazônidas; narrativas; singularidades.

\section{TALES AND CHARMS CHILDISH AMAZONIAN RIVERAIN IN SCHOOL EVERYDAY}

\begin{abstract}
Zigzagging between the riverain and Amazonian childish compositions we compose this text. We are committed to narrating the singularities of children who flee from pre-set interpretations and itineraries, because in our meeting, we stop at their clever and clandestine operations little observed in the world taken by capitalism. In the wake of the difference philosophy, we have been producing differentiations in the ways of researching with children and childhoods. For this, we produced our investigative path through Deleuzian cartography in the search for children's experiences and narratives. In this endowment, on the banks of a river in the middle of the Amazon rainforest, we find the narratives of singular experiences that subvert the logic of meaning of a place for children and childhoods at school.
\end{abstract}

Keywords: amazonian riverain children; narratives; singularities.

\section{CUENTOS Y ENCANTOS NIÑOS RIBERA AMAZÓNICA EN LA ESCUELA TODOS LOS DÍAS}

Resumen

Zigzagueando entre las composiciones infantiles ribereñas y amazónicas componimos este texto. Nos comprometemos a narrar las singularidades de los niños que huyen de interpretaciones e itinerarios preestablecidos, porque en nuestra reunión, nos detenemos en sus operaciones inteligentes y clandestinas poco observadas en el mundo tomado por el capitalismo. A raíz de la filosofía de la diferencia, hemos estado produciendo diferenciaciones en las formas de investigación con niños y niñas. Para esto, produjimos nuestro camino de investigación a través de la cartografía deleuziana en la búsqueda de experiencias y narrativas infantiles. En esta investidura, a orillas de un río en medio de la selva amazónica, encontramos las narraciones de experiencias singulares que subvierten la lógica del significado de un lugar para niños y niñas en la escuela.

Palabras clave: niños de la ribera amazónica; narrativas; singularidades. 


\section{INSPIRAÇÃO}

\section{O privilégio insetal de ser uma borboleta me atraiu. \\ Por certo eu iria ter uma visão diferente dos homens e das coisas. (Manoel de Barros)}

Entre os vazios e os cheios escrevemos este texto oriundo de uma pesquisa realizada entre crianças ribeirinhas que vivenciam suas feituras infantis no espaçotempo ${ }^{1}$ amazônico. Assumimos o compromisso de narrar "práticas comuns", as "artes de fazer" de crianças que fogem de interpretações e itinerários prefixados, pois em nosso encontro, nos detemos em suas operações astuciosas e clandestinas pouco observadas no mundo tomado pelo capitalismo. Aprendemos com Certeau a importância de narrar as práticas comuns do dia a dia, a "[...] introduzir as experiências particulares, as frequentações, as solidariedades e as lutas que organizam o espaço onde as narrações vão abrindo caminho" (CERTEAU, 1998, p. 35).

Por assim dizer, fomos ao encontro de potencialidades de vidas que pululam com a vida ordinária e encontramos crianças que "ainda" não foram tomadas pela exacerbação do mundo capitalista, estão em meio à floresta amazônica subvertendo a ordem dos espaços destinados às crianças. As infâncias que potencializamos, neste texto, se atualizam naquilo que Certeau (1998) chama de "artes de fazer", "astúcias sutis", "táticas de resistência" que vão alterando os objetos, os códigos e estabelecendo uma apropriação do espaço e do uso ao jeito de cada um. O autor acredita nas possibilidades de uma multidão anônima abrir o próprio caminho no uso dos produtos impostos pelas políticas culturais, numa liberdade em que cada uma procura viver, do melhor modo possível, a ordem social e a violência das coisas ${ }^{2}$. Este foi o deslocamento proposto pela pesquisa que se ocupou com as "artes de fazer" dos praticantespensantes", na busca da compreensão de suas regras próprias e de seu desenvolvimento (CERTEAU, 1998, p. 142).

Lado a lado e de cabeça para baixo com os infantis ribeirinhos, engendramos novos rumos e novos modos de fazer pesquisa em educação, pois à medida que caminhávamos entre o espaçotempo de indeterminação amazônico, fomos saboreando os cheiros e as coisas daquele espaço que movimenta o cotidiano das vidas ribeirinhas. O espaçotempo da pesquisa encontra-se em meio à floresta amazônica, abrigando algumas comunidades ribeirinhas ao longo de um rio, o lugar denomina-se Reserva Extrativista Guarida-Roosevelt. À vista disso, compusemos nosso trajeto investigativo, dispusemos de uma cartografia deleuziana na busca do toque, das vivências e do palpitar das palavras que, de maneira nenhuma, podíamos antecipar. Durante a pesquisa, carregávamos em nosso íntimo muitas inquietações, contudo a principal pergunta que movia e latejava nossos pensamentos era: como as crianças ribeirinhasamąônidas manifestam, em meio à floresta, seus saberes infantis na escola? O que potencializa as vivências infantis ribeirinhas?

Assim, nossa trilha de pesquisa se fez cartografando os movimentos cotidianos de crianças ribeirinhas, que ora estavam na beira do rio brincando, pulando, nadando ou pescando, ora estavam em sala de aula. Para acompanhá-las, nos posicionamos no local da escuta e nos

\footnotetext{
$1 \mathrm{O}$ modo de escrever estes termos juntos e grafados em itálico - tais como os termos ribeirinhasamazônidas, espaçotempo, praticantespensantes, entre outros - é utilizado em pesquisas nos/dos/com os cotidianos e serve para nos indicar que, embora a forma dicotomizada de criar conhecimentos na sociedade moderna seja, ainda hoje, hegemônica, tem significado limites ao desenvolvimento de pesquisas nessa corrente de pensamento.

${ }^{2}$ Notas na contracapa do livro de Michel de Certeau. A invenção do cotidiano: 1, Artes de fazer.

3 Termo apresentado por Oliveira (2012), indo além da ideia de Certeau que os chama somente "praticantes", mas coerente com o pensamento deste autor que diz que esses criam conhecimentos, significações permanentes no desenvolvimento de suas ações cotidianas.
} 
deslocamos entre o espaçotempo por elas habitado e aí encontramos as "artes de fazer" infantis que compõem suas vidas.

\section{CARTOGRAFIAS INFANTIS RIBEIRINHASAMAZÔNIDAS}

Sabemos que as crianças estão por toda parte, em lugares nem sempre convencionais e, mais que isso, são pessoas com as quais raramente podemos agendar ou marcar hora específica e estabelecer critérios, portanto, habitamos por alguns dias o espaçotempo em que vivem, acompanhando-as em seu dia a dia, sem hora e lugar marcado. Nos encontros, foi possível criar muitos momentos de interação e conversas pelas quais expuseram saberes, fazeres, dizeres e sentires de suas vivências amazônicas.

Acompanhamos os movimentos das crianças nos diferentes espaçostempos em que vivem, conversamos com elas, com suas famílias, com professores e outros protagonistas que ali habitam. Anotamos, fotografamos, cartografamos e implicamo-nos com aquela realidade à beira rio. Essa é uma finalidade da cartografia, pois incita o pesquisador a inventar caminhos e contornos em meio àquilo que o instiga a conhecer. A cartografia, como método, proporciona a investidura em pesquisar o que acontece na superfície do vivido e do vivível, acompanha um processo sempre em movimento e o percebe como algo incompleto, sempre em vias de ser-aí, transitório. A pesquisa cartográfica se faz como um mapa movente, contorna e descontorna espaçostempos, subjetividades e vivências. É um mapa com múltiplas entradas, por meio do qual é possível se movimentar livremente. Nas palavras dos autores:

O mapa é aberto, é conectável em todas as suas dimensões, desmontável, reversível, suscetível de receber modificações constantemente. Ele pode ser rasgado, revertido, adaptar-se a montagens de qualquer natureza, ser preparado por um indivíduo, um grupo, uma formação social. Pode-se desenhá-lo numa parede, concebê-lo como obra de arte, construí-lo como uma ação política ou como uma meditação. [...] Um mapa é uma questão de performance (DELEUZE; GUATTARI, 1995, p. 22).

Cartografar consistiu em produzir mapas que nos levassem pelos rastros infantis para conhecer e sentir os atravessamentos que perpassam a vida daqueles praticantespensantes dos cotidianos. Com isso, a pesquisa cartográfica oportunizou movimentos contínuos para afetarmos e sermos afetadas, para conhecermos, vivenciarmos, sentirmos e habitarmos experiências com as crianças na tessitura da pesquisa. A cartografia não é uma possibilidade de representação da realidade e nem algo que oferece a interpretação do binarismo certo/errado, mas se apresenta como um movimento de pesquisa inventivo, rizomático, que oferece elementos a serem experimentados e criados na superfície. Desse modo, a cartografia da pesquisa se fez junto às crianças ribeirinhasamazônidas, no intuito de proporcionar encontrosconversas para narrarem suas "artes de fazer" crianceiras, em meio à floresta amazônica que também se faz presente no currículo do cotidiano da escola.

Intentamos trazer as narrativas das crianças para que possam evidenciar outras práticas vividas por uma infância que não segue um sistema de repetição. Neste caso:

Interrompendo a narração da historiografia dominante e articulando historicamente o passado com o presente, é possível percebermos as histórias que acontecem no presente, que o constituem a cada dia e que podem se traduzir em histórias que se desviaram do curso dominante, que resultam no sempre igual (MALDONADO, 2017, p. 15). 
Narrar a vida é um exercício de produção do que Benjamin (1987) chama de forma artesanal de comunicação. Trazer as narrativas para o texto e explicitá-las consiste em ato político para que elas não se percam por não serem mais ouvidas e para que possam ser, novamente, narradas. Para Benjamin (1987, p. 198), “[...] as melhores narrativas escritas são as que menos se distinguem das histórias orais contadas pelos inúmeros narradores anônimos". Narrar é uma arte artesanal para aquele que semeia a palavra e para o ouvinte que saboreia contos e encantos das histórias de vidas reais. Benjamin (1987, p. 201) nos lembra da importância da sabedoria e, principalmente, o quanto essa prática está desaparecendo: "A arte de narrar está definhando porque a sabedoria - o lado épico da verdade - está em extinção". Portanto, escolhemos a inscrição das narrativas como aposta política e metodológica dos acontecimentos da pesquisa.

\section{SINUOSIDADES CRIANCEIRAS RIBEIRINHASAMAZÔNIDAS}

As redes de conversação que tecemos constituíram procedimento privilegiado da pesquisa, pois consolidaram-se ao conversar, brincar, ouvir, sentir e conviver com as crianças ribeirinhas no espacotempo em que habitam. Nessa experiência, compreendemos o que Deleuze (1995) chama de devir e, assim, trazemos para esse texto o devir-criança que habita em nós. Observamos que a vida ribeirinha segue devagar, no sentido de subverter nosso mundo consumista, capitalista, excedido pelo trabalho. Os ribeirinhos [participantes da pesquisa], não se preocupam com o acúmulo de bens, vivem de acordo com os períodos de safras (castanha e seringa), caçam, preenchem seus tempos com visitas aos vizinhos, contação de causos ${ }^{4}$, contemplação do rio, das árvores, dos animais. Vivem livres de um mundo tomado por um capitalismo selvagem que exige sempre mais de nós mesmos.

Desse modo, concordamos com Maldonado (2017, p. 51-52) quando afirma:

Ao contrário desse sujeito que vive a experiência individual (Erlebinis), a população ribeirinha pode ser entendida como sujeitos da experiência coletiva (Erfahrung), sujeitos do acontecimento, sujeitos que se deixam afetar pela possibilidade de algo que lhes passe ou lhes aconteça ou thes toque.

Esse modo de viver minuciosamente a experiência coletiva exige uma interrupção no tempo, como nos cita Larrosa (2004, p. 160):

Requer parar para pensar, para olhar, parar para escutar, pensar mais devagar, olhar mais devagar, escutar mais devagar; parar para sentir, sentir mais devagar, demorar-se nos detalhes, suspender a opinião, suspender o juízo, suspender a vontade, suspender o automatismo da ação, cultivar a atenção e a delicadeza, abrir os olhos e os ouvidos, falar sobre o que nos acontece, aprender a lentidão, escutar os outros, cultivar a arte do encontro, calar muito, ter paciência e dar-se tempo e espaço.

Assim, nós, pesquisadoras, aceleradas pelo tempo cronometrado e do mundo do trabalho exaustivo, em meio a infâncias urbanizadas, interrompemos nossos pensamentos sobre, e abrimo-nos a uma nova possibilidade de encontro com as infâncias e as crianças ribeirinhas, nos colocamos no lugar da escuta e ouvimos movimentos disformes, típicos de uma criação sem órgãos $(\mathrm{CSO})^{5}$ que sobrepujam e resistem à ordem dominante. Como nas narrativas a seguir:

\footnotetext{
${ }^{4}$ Histórias que narram fatos verídicos ou não.

5 O corpo sem órgãos não é um corpo morto, mas um corpo vivo, e tão vivo e tão fervilhante que ele expulsou o organismo e sua organização. [...] O corpo pleno sem órgãos é um corpo povoado de multiplicidades (DELEUZE; GUATTARI, 1995, p. 42).
} 
Ana $^{6}$ : Professora, na época da seca a gente desce o rio rumo o Amazonas. O rio baixa as águas e fica cheio de praias. A gente vai acampar com a mamãe e o papai, daí a gente pesca e assa peixe nas praias. Eu gosto muito de pescar. Uma vez, professora, a gente foi pescar. Tava na época da cheia. Minha mãe falou pra não descer o rio, era pra gente subir. Mas a gente queria ir no poção. Então, pegamos a canoa, eu, a Lívia e a Tauana, e descemos o rio remando. A gente foi pescando de caniço. Quando chegamos perto do poção, já tinha pegado um bocado de peixe, a canoa alagou, quase caímos numa cachoeira. Sorte que a gente pulou da canoa e tiramos água da canoa muito rápido, mas perdemos tudo os peixes que tinha pescado. Mas, nosso medo era dos jacarés, porque nesse rio tem muito jacaré pra todo lado. (Ana, 2015, 8 anos. Fonte: diário de campo).

Bill: É, professora, aqui na colocação, a gente pesca todo dia. Todos os dias alguém é escolhido pra pesca. Mamãe logo cedo grita: "hoje quem vai pescar?" Eu sempre quero ir, mas papai não deixa ir com as meninas, só quando ele vai, às vezes ele me leva. Papai tem medo do barco alagá comigo dentro. Mas eu sei nadar. Também sei pescar de linhada e de caniço. (Bill, 2015, 6 anos. Fonte: diário de campo).

$\mathrm{Na}$ vida infantil ribeirinhaamazônida, encontramos a possibilidade de contar a história de seus devires que, na escorregada imprevisível da razão, também habita os espaçostempos da escola. Para Deleuze e Guattari (1997, p. 76):

O devir é limiar que provoca outros devires que nunca tomam forma acabada, pois eles próprios são um desmanchamento de formas, dependentes das alianças e agenciamentos que os desencadeiam. [...] Devires abrem portas, estão sempre entre, numa zona de indiscernibilidade, constituindo como que uma vibração. Assim, devires sempre tiram do lugar "confortável" habitado por identidades e formas bem contornadas. [...] Devires são fluxos que podem contagiar ou não, mas que, sobretudo, arrancam das identidades maiores, dos metros-padrão. O devir é sempre minoritário.

Desse modo, as forças intensivas que atravessam os corpos infantis podem desencadear possibilidades criadoras de outros modos de pensar e viver o mundo, distintos daqueles que nossos discursos performativos, baseados em discursos totalizantes, enunciam sobre as crianças e as infâncias.

O mundo em que a criança vive suas relações com o outro é um claro-escuro de verdade e engano. Neste mundo a verdade não é dada, não está acabada, impressa de forma imutável na consciência humana; a verdade é algo que se faz constantemente nas relações sociais e por meio delas (JOBIM e SOUZA, 1994, p. 154).

Pensar um mundo em que claro e escuro, verdade e engano se misturam, aponta para um desvio que forja a captura de um mundo padronizado. Ver o mundo em desvio que se constitui mutuamente e não prefixado, nos proporciona sentir a multiplicidade que ali existe. Assim, presenciar os ritmos de vidas singulares muda o jeito de ver/pensar/conviver de quem se aventura a novos caminhos, contrapondo-se aos processos maquínicos do mundo capitalístico que, segundo Guattari e Rolnik (1996, p. 16), “[...] produz indivíduos normalizados, articulados uns aos outros segundo sistemas hierárquicos, sistemas de valores, sistemas de submissão".

\footnotetext{
${ }^{6}$ Os nomes das crianças são fictícios, em conformidade com o Comitê de Ética e Pesquisa (CEP).
} 
As crianças ribeirinhasamąônidas subvertem a ordem dominante, apresentam suas singularidades num instante fugidio em vias de ser-aí, uma vez que, atravessadas por agenciamentos com o meio, interagem com as redes de vivências que as interpelam e engendram novos modos de viver e sentir a vida. Em outras palavras, o que a criança ribeirinha faz é produzir uma nova percepção de mundo. A essa outra maneira de encontrar com o mundo Guattari e Rolnik (1996, p. 17) dão o nome de singularização, ou seja:

Uma maneira de recusar todos esses modos de encodificação preestabelecidos, todos esses modos de manipulação e de telecomando, recusá-los para construir, de certa forma, modos de sensibilidade, modos de relação com o outro, modos de produção, modos de criatividade que produzam uma subjetividade singular. Uma singularização existencial que coincida com um desejo, com gosto de viver; com uma vontade de construir o mundo no qual nos encontramos, com a instauração de dispositivos para mudar os tipos de sociedade, os tipos de valores que não são os nossos.

Dessa maneira, as crianças ribeirinhasamazônidas instituem sua subjetividade constituindo suas singularidades por intermédio das ressonâncias de suas vivências e da criação de seu próprio estilo de vida. Essas singularidades atravessam o espaşotempo da escola e fervilham no currículo dos cotidianos escolares como forma de resistência ao currículo instituído pois, por muitas vezes, encontramos um currículo que não condiz com as experiências infantis. Nesses termos, Alves (2015, p. 93) complementa:

[...] a existência de um curriculo oficial, afirmado e reafirmado que o necessário é o mínimo, o conteúdo e a forma mínimos, e que se garante à maioria, a posse, exclusivamente, daquilo que os que decidem consideram como apropriado, básico, ao nível daqueles que vão receber o que é dado. Ao mesmo tempo, o que estes têm/sabem continua sendo considerado de pouca ou nenhuma valia. Ao lado, portanto, do currículo oficial cria-se outro, que não quer se ver/ ouvir/tocar/sentir, composto por tudo aquilo que não foi selecionado, normalizado, hierarquizado, ou seja, o tudo mais, o muito mais - o currículo negado (grifos da autora).

A previsibilidade do currículo é colocada em questão a cada novo encontro com os cotidianos das escolas (distintos entre si), pois existem saberes e fazeres que são negados pelo currículo instituído, mas que insistem em permanecer no dia a dia da escola, pululando com a vida, nos mostrando que existem conhecimentos além dos fixados nas matrizes curriculares. Como nos alerta Certeau (1998, p. 222), “[...] por trás das portas de nossas cidades, no próximo distante dos campos, existem vastas pastagens poéticas e pagãs onde falem ainda os cantos, os mitos e o proliferante sussurro". Ou seja, nos vastos espaçostempos de nossa sociedade existem as vivências nos/dos/com os cotidianos que estão de fato na escola, também, movimentando os praticantespensantes escolares. Assim, as brincadeiras crianceiras ribeirinhas e as experiências dos cotidianos amazônicos fogem do que estamos acostumados enquanto seres individuados e donos do saber e poder e compõem o cotidiano da escola do campo ribeirinha. Observem-se as composições do cotidiano ribeirinho na narrativa do Antônio:

Antônio: Professora, eu e o José sempre brincava debaixo da mangueira apanhando cobrinha debaixo da tábua, a gente tinha uma baladeirinha7. Daí um

\footnotetext{
7 Baladeirinha é um brinquedo, denominado assim pelas crianças ribeirinhas. É uma espécie de bifurcação (ou forquilha) de madeira retirada da floresta pelas próprias crianças, em que se amarra, em cada extremidade, uma borracha para atirar pedras e brincar de caçar. Fonte: diário de campo da pesquisa.
} 
dia a gente estava debaixo da mangueira, meu tio apareceu e disse que viu um negócio marrom que estava se mexendo em cima da árvore. Meu tio disse que era uma cobra que parecia jiboia. Aí, meu tio, subiu na mangueira e balaram, balaram até que mataram ela. Eles mediram a cobra, dava uns 4 metros de tamanho. Daí quando toraram a cobra, ela tinha engolido quatro morcegos. (Antônio, 2015, 6 anos. Fonte: diário de campo).

Ouvir as "artes de fazer" infantis ribeirinhas da Amazônia é algo que interrompe nossas verdades, pois é comum induzirmos e sujeitarmos as crianças ao controle de nossas políticas de acolhimento, regras e normas, mas, no mesmo movimento e, paradoxalmente, elas nos desafiam a dar respostas e se rebelam. Enfim, estranham-se a partir do sufoco gerado por esse processo e nos mostram um mundo regado de estranhamentos, reveladores dos desejos de escapar aos discursos oficiais destinados a elas. Nessa perspectiva, as crianças são protagonistas ao exercerem sua dinâmica, sua lógica interna, enfim, sua pulsação.

Para a autora Alves (2009, p. 7), “[...] a criação de conhecimentos e significações nos cotidianos segue caminhos variados e complexos, diferentes daqueles que construímos nas ciências ou nas instituições nas quais a sociedade moderna foi se organizando". Assim, os saberes e fazeres criados nas relações infantis ribeirinhasamazônidas com o espaçotempo de subjetivação escolar, nos levam a questionar a nossa concepção de criança e infância que, se seguir um caminho já traçado previamente, chega a um final feliz. Não. O contato com essa realidade nos leva a perceber que as experiências infantis amazônidas quebram uma certa linearidade que o pensamento moderno nos impôs. Vivenciar essa realidade nos torna outras em relação à ideia de criança e infância. Aquele ideal que o pensamento ocidental traz, de criança como promessa, como futuro, como amanhã é completamente paralisado quando se abre a barriga de uma cobra e se encontra morcegos nela... As crianças ribeirinhasamazônidas intercambiam experiências. Isso observamos na narrativa do Felipe.

Felipe: Esses dias, professora, eu e meu pai estávamos no pique da castanha ${ }^{8}$, de repente vimos uma cobra da grossura de uma panela de pressão. Ela estava passando e quando viu a gente veio pro nosso rumo. Deixamos o balaio de castanha e corremos muito, porque a gente estava sem a espingarda. Depois de um tempão a gente voltou no pique de castanha e vimos dois buracos bem grandes, mas não vimos se ela entrou no buraco. Pegamos nosso balaio de castanha e fomos embora rapidinho.

Professoras9: E você conseguiu ver qual cobra era?

Felipe: Ah, professora! Ela tinha umas manchas, tipo uns oito no couro dela. Quando ela veio gritando pro nosso lado, a gente correu de medo. Voltamos só depois que ela parou de gritar.

Professoras: E cobra grita?

Felipe: Professora, no meio da floresta, a cobra grita... (Felipe, 2015, 7 anos. Fonte: diário de campo)

Larrosa (2015, p. 18) pontua que “[...] a experiência é o que nos passa, o que nos acontece, ou o que nos toca". As experiências narradas pelos meninos ribeirinhos com as cobras é um acontecimento vivido que lhes passa e lhes toca, pois são acontecimentos eminentemente produzidos e praticados. Trata-se de acontecimentos comuns para eles, mas a experiência que vivenciaram é impossível de ser repetida. Para Deleuze (1974, p. 152), o acontecimento é efeito

\footnotetext{
8 A expressão "pique de castanha", refere-se ao "caminho da castanha". Local que fica o castanhal de cada colocação. Nas populações ribeirinhas extrativistas cada família tem um caminho da castanha.

${ }_{9}^{9}$ As crianças ribeirinhasamazônidas chamavam as pesquisadoras de professoras.
} 
de superfícies, impossíveis de serem capturados, “[...] ele [o acontecimento] é o que deve ser compreendido, o que deve ser querido, o que deve ser representado no que acontece". Então, o que acontece na superfície traz em suas margens a possibilidade de criar pensamentos e modos outros de encontros com o mundo. Nas assertivas do autor:

Os acontecimentos, na sua diferença radical em relação às coisas, não são mais em absoluto procurados em profundidade, mas na superfície, neste tênue vapor incorporal que se desprende dos corpos, película sem volume que os envolve, espelho que os reflete, tabuleiro que os torna planos (DELEUZE, 1974, p. 26).

As narrativas infantis ribeirinhas estão no que acontece no cotidiano de suas vidas amazônidas, não estão escritas em conhecimentos científicos ou em redes de informação. São experiências singulares que produzem diferenciações de sentido em cada um, e que é afetado por elas. As experiências de vida à beira de um rio em meio à floresta amazônica, numa reserva extrativista, na escola, não são apreendidas para serem repetidas ou passivamente transmitidas. Elas acontecem no criar, no potencializar a vida, nas diferenças e no despraticar as normas. As crianças ribeirinhasamazônidas despraticam as normas quando se compõem com o rio que se mistura a seus corpos e a suas almas. Esse encontro cotidiano rompe o limite do perigo, do profundo, do cuidado e do medo. Estes são momentos ímpares, irrepetíveis em que acontece a diferença.

A diferença traz sinuosidades infantis para dentro da sala de aula, os aprendimentos infantis ribeirinhos mostraram que os saberes e fazeres dos cotidianos fazem parte do "uso" que se pode fazer no dia a dia com o currículo instituído, mostrando que há uma infinidade de ritmos, acordes e arpejos para experimentar. Cada praticantepensante traz consigo suas "artes de fazer" do cotidiano e, juntas, podem ser aplicadas em sala de aula, no intuito de envolver as práticas instituídas com o instituinte, atribuindo sentido à vida vivida, valorizando a vida ribeirinha que se faz presente dentrofora da escola. Segundo os autores Ferraço e Carvalho (2012, p. 5), na escola pode-se "[...] buscar privilegiar as conversações e narrativas como inseridas em fluxos de movimentos e ações, transformando a cultura da escola e a si mesmas, na perspectiva de atualização de virtualidades do cotidiano".

Assim, as crianças ribeirinhasamazônidas, ao criaram sentidos outros no espaçotempo em que acontecem suas vivências, produziram uma espécie de involução criadora que rompe com os dogmas e a nossa soberba de sempre saber tudo sobre as crianças, as infâncias e as práticas de ensino.

Os praticantes do cotidiano tecem alternativas práticas com os fios que as redes das quais fazem parte, dentro e fora da escola, lhes fornecem. Sendo assim, pode-se dizer que existem muitos currículos em ação nas escolas, apesar dos diferentes mecanismos homogeneizadores (FERRAÇO, CARVALHO, 2012, p. 10 , grifo dos autores).

Os processos hegemônicos elegem pessoas e os autorizam a criar políticas educativas e práticas de ensinoaprendizagem, naturalizando a ideia de que o que essas pessoas criam, podem e devem "caber" em todas as escolas, seja qual for a sua realidade. Para Alves (2009, p. 9):

Os múltiplos processos cotidianos de "lidar com a vida", em sua infinita condição de "criar saídas", não são sequer imaginados pelo modo hegemônico de criar, que não os consegue ver, já que eles não contam com um lugar próprio, como o que a maquinaria panóptica dominante tem. Ou seja, os praticantes dos cotidianos, o tempo todo, aproveitam a ocasião que esta cegueira dos processos hegemônicos permite, atuando nos mesmos lugares nos quais estes se realizam. (grifos da autora) 
As crianças ribeirinhas amazônidas, no momento em que podem, desvencilham-se das amarras de um processo educativo hegemônico e atuam conforme o seu cotidiano, preenchendo o espacotempo da sala de aula com suas narrativas compostas por saberes, fazeres, sentires e vivências.

\begin{abstract}
Aqui não há mais absolutamente formas e desenvolvimentos de formas; nem sujeitos e formações de sujeitos. Não há nem estrutura nem gênese. Há apenas relações de movimento e repouso, de velocidade e lentidão entre elementos não formados, ao menos relativamente não formados, moléculas e partículas de toda espécie. Há somente hecceidades, afetos, individuações sem sujeito, que constituem agenciamentos coletivos. Nada se desenvolve, mas coisas acontecem com atraso ou adiantadas, e formam esse ou aquele agenciamento de acordo com suas composições de velocidade. Nada se subjetiva, mas hecceidades formam-se conforme as composições de potências ou de afetos não subjetivados (MONTEIRO, 2009, s. p.).
\end{abstract}

Essas crianças afirmam suas singularidades a partir de sua individuação ao modo de apreenderviverpensarproduzir o mundo através de suas experiências. Como nos afirma Silvestri (2010, p. 122), "[...] as crianças produzem uma cultura plural e ao mesmo tempo singular, pois expressam de um modo muito particular (próprio das crianças) as maneiras de agir no mundo - o seu mundo". As crianças ribeirinhasamazônidas tecem suas vivências, suas brincadeiras, histórias e produzem um currículo instituinte que muito tem a dizer no campo educacional.

Essa é apenas uma das múltiplas maneiras que "as crianças ordinárias" encontram para transgredir as regras instituídas e acreditar nas possibilidades encontradas no cotidiano, para a criação de uma escola mais significativa. Certeau (1998, p. 40) propõe, como baliza teórica, "[...] a construção de frases próprias com um vocabulário e uma sintaxe recebidos", supondo que, pelas táticas de usar essa produção, pelas invenções cotidianas, pelas artes de fazer, ocorra "[...] uma bricolagem com e na economia cultural dominante, pela possibilidade de descobrir inúmeras metamorfoses da lei, segundo seus interesses próprios e suas próprias regras" (CERTEAU, 1998, p. 40). A partir disso, concebemos que as crianças ribeirinhasamazônidas promovem a resistência diante de um currículo escolar homogeneizador.

Há uma invenção de novos hábitos, novos saberes e fazeres que acabam por criar "outros modos" nas "artes de fazer" dentrofora da escola. As experiências expressas pelas crianças ribeirinhasamazônidas concebem a arte, o uso e os saberes e fazeres dos cotidianos. Dessa maneira, entrecruzando o espaçotempo infantil ribeirinho, ora em meio à floresta, ora na escola, encontramos as narrativas que potencializam as singularidades das crianças ribeirinhasamazônidas. $\mathrm{Na}$ possibilidade desse encontro, presenciamos o movimento do cotidiano de crianças teimosas, inventivas, substantivas muito mais que adjetivas, viventes no mundo como achadouras daquilo que nos escapa porque, como adultos, não somos capazes de "ver", "olhar", "sentir" o enigma das infâncias. As crianças ribeirinhasamazônidas escovam esse mundo - dotado de normas e regras fundadas em discursos opressivos - a contrapelo, resistem e põem em movimento o currículo da escola.

\title{
O (DES)PROPÓSITO DE UM FIM
}

Compor as cartografias das vivências infantis ribeirinhasamazônidas possibilitou a fuga do poder domesticador dos decalques da realidade para entrar numa cartografia intensa. Produzimos mapas não como imagem pronta, fixa e estabilizada de um lugar; inventamos mapas como acontecimento e ruptura; fizemos mapas atravessados por movimentos de criação, no intuito de 
instituir lugares, afetos e sensações. Por meio das narrativas das crianças ribeirinhas, nos aproximamos das infantilices e dos momentos crianceiros singulares e irrefazíveis, pois as crianças e suas infâncias são algo que sempre nos escapam, "[...] na medida em que inquieta o que sabemos (e inquieta a soberba de nossa vontade de saber), na medida em que suspende o que podemos (e a arrogância da nossa vontade de poder)" (LARROSA, 2015, p. 185). Colocam sob suspense nossos devaneios e delírios de sempre "saber o que fazer com elas", resistem aos nossos planos de captura de suas subjetividades no momento em que conseguem questionar nossas práticas de acolhimento e de estabelecimentos de ensino.

A alteridade nas/das infâncias está naquilo que não sabemos delas, por isso só podemos dizer sobre a marca de seus rastros, aguçar nossa sensibilidade de escutá-las e oferecer a elas lugares (no plural) que reverberem suas meninices e peraltagens infantis, para que possam viver e expandir as "artes de fazer" das infâncias artistas e criativas de singularidades, para que, com isso, possam criar suas experiências infantis e potencializar a vida e o espaçotempo da escola. Pesquisar as infâncias das crianças ribeirinhasamazônidas que vivem num espaçotempo diferente daquilo que estamos acostumados a ver, é, nesse contexto, problematizar o quanto elas correspondem às infâncias que conhecemos.

É nos questionarmos sobre qual é o efeito das práticas e estratégias de saber e poder que exercemos sobre elas. É mostrar como os discursos e as narrativas que se pronunciam sobre a infância têm orientado os modos de subjetivação que atuam na constituição de suas subjetividades. É reconhecer que no currículo escolar se corporificam as relações de saber e poder e, também, corporifica-se um campo contestado, caótico, rizomático, com fluxos, movimentos, ritmos e arpejos provindos dos agenciamentos e das vivências dos cotidianos dos praticantespensantes. É, de alguma maneira, questionar as narrativas que definem "o que é ser criança". Trazer à cena a vida infantil que pulsa em meio à floresta amazônica implica perceber que não existe um verdadeiro "ser criança" que paira no ar. Existem crianças em seus distintos modos de vida que fervilham suas "artes de fazer" dentrofora dos espacostempos dos currículos das escolas e produzem resistências ao modo capitalístico de escolarização.

\section{REFERÊNCIAS}

ALVES, Nilda. Apresentação da série Cotidianos, imagens e narrativas. In: Salto para o futuro. Ano XIX - n. 8 - jun. 2009.

ALVES, Nilda. Praticantepensante de cotidianos. Belo Horizonte: Autêntica, 2015.

BARROS, Manoel de. Poesia completa. São Paulo: Leya, 2010.

BENJAMIN, Walter. Obras escolbidas. Magia e técnica, arte e política: ensaios sobre literatura e história da cultura. São Paulo: Brasiliense, 1987.

CERTEAU, Michel de. A invenção do cotidiano: 1. Artes de fazer. Petrópolis, Rio de Janeiro: Vozes, 1998.

DELEUZE, Gilles. Lógica do sentido. Tradução de Luiz Roberto Salinas Fortes. São Paulo: Perspectiva, Ed. USP, 1974 (Estudos, 35).

DELEUZE, Gilles; GUATTARI, Félix. Mil platôs: capitalismo e esquizofrenia. São Paulo: Ed. 34, v. 1, 1995.

DELEUZE, Gilles; GUATTARI, Félix. Mil platôs: capitalismo e esquizofrenia. São Paulo: Ed 34, v. 4, 1997. 
FERRAÇO, Carlos Eduardo; CARVALHO, Janete Magalhães. Currículo, cotidiano e conversações. Revista E-curriculum. São Paulo, v. 8, n. 2, ago. 2012. Disponível em: http://revistas.pucsp.br/index.php/curriculum. Acesso em 20 jun. 2015.

GUATTARI, Félix; ROLNIK, Suely. Micropolitica: cartografias do desejo. 4. ed. Petrópolis: Vozes, 1996.

JOBIM e SOUZA, Solange. Infância e linguagem: Bakhtin, Vygotsky e Benjamin. Campinas, São Paulo: Papirus, 1994.

LARROSA, Jorge. Linguagem e educação depois de Babel. Belo Horizonte: Autêntica, 2004.

LARROSA, Jorge. Pedagogia profana: danças, piruetas e mascaradas. Belo Horizonte: Autêntica, 2015.

MALDONADO, Maritza Maciel Castrillon. Espaço Pantaneiro: cenário de subjetivação da criança ribeirinha. Curitiba: CRV, 2017.

MONTEIRO, Silas Borges. Hecceidade como individuação sem sujeito. Disponível em: https://egrifo.wordpress.com/2011/02/26/hecceidade-como-individuacao-sem-sujeito/. Acesso em 4 nov. 2019.

OLIVEIRA, Inês Barbosa de. Aprendendo nos/dos/com os cotidianos a ver/ ler/ouvir/sentir o mundo. Educ. Soc. Campinas, v. 28, n. 98, p. 47-72, jan./abr. 2007. Disponível em: http://www.scielo.br/scielo.php?script=sci_arttext\&pid=S0101-73302007000100004. Acesso em 12 out. 2015.

Submetido em março de 2020

Aprovado em março de 2020

\section{Informação das autoras:}

Edilma de Souza

Doutoranda no Programa de Pós-graduação em Educação da Universidade Federal de Mato Grosso

E-mail: edilmasz84@gmail.com

ORCID: https://orcid.org/0000-0002-7802-8201

Link. Lattes: http://lattes.cnpq.br/5408374233356566

Maritza Maciel Castrillon Maldonado

Professora Titular na Universidade do Estado de Mato Grosso

E-mail:maritzacmaldonado@gmail.com

ORCID: https://orcid.org/0000-0001-6574-4463

Link lattes: $\underline{\text { http://lattes.cnpq.br/4975506800952806 }}$ 